\title{
Association Between Gut Flora and Response to Antiviral Therapy in Chronic Hepatitis C Patients
}

\author{
Reda Mohamed Salem El-Badawy, MD', Mohammed El-Sayed El-Shewi, MD', \\ Naglaa Fathy Ebrahim Al-Husseini, PhD², Rasha Abdel-Hameed El-Sayed Ali, PhD ${ }^{3}$, \\ Ebrahim Mohammedy Ebrahim Mohammed, M.B.B.Ch ${ }^{4}$ \\ ${ }^{1}$ Hepatology, Gastroenterology and Infectious Diseases Department, Faculty of Medicine, Benha \\ University, Benha, Egypt. \\ ${ }^{2}$ Medical Biochemistry and Molecular Biology Department, Faculty of Medicine, Benha University, \\ Benha, Egypt, \\ ${ }^{3}$ Microbiology and Immunology Department, Faculty of Medicine, Benha University, Benha,Egypt. \\ ${ }^{4}$ Hepatology, Gastroenterology and Infectious Diseases Department, Mabaret El-Maadi Hospital, Cairo, \\ Egypt.
}

Corresponding Author Ebrahim Mohammedy Ebrahim Mohammed

Mobile:

01144328766

E mail:

dr.ebrahim2010@yaho o.com

Short title: Gut microbiota in chronic HCV patients

Key words:

Direct Acting Antivirals (DAAS), Hepatocellular Carcinoma (HCC), Hepatitis $C$ Virus (HCV)
Background and study aim: Still there is percentage of $\mathrm{HCV}$ patients not responding to Direct Acting Antiviral Agents (DAAS), even the responder $\mathrm{HCV}$ patients need to follow up. Gut flora (Microbiota) include all the microorganisms in the intestine and liver can be greatly affected by changes in gut microbiota. The study was done to evaluate the association between gut flora and the response to DAAS in chronic HCV patients.

Methodology: Two groups; group 1 ( $\mathrm{No}=15$ of $\mathrm{HCV}$ responders patients) and group $2(\mathrm{No}=15$ non responder $\mathrm{HCV}$ patients) treated by DAAS according to the treatment protocol of the Egyptian National Committee for Control of Viral Hepatitis (NCCVH). Healthy control subjects $(\mathrm{No}=15)$ age and sex matched to the study groups as third group. All investigations were done plus stool culture using VITEK 2 KITS according to the manufacturer.
Results: The results show statistically significant difference between the patients (responders and non responders) and control, where p1 comparison between control and responders, p2 between control and non responders, p3 between responders and non responders. Enterobacter organism in p2, p3 was $<0.001$ and $<0.005$ respectively. Proteus and Clostridium perfringens in $\mathrm{p} 2$ was 0.009 and 0.04 respectively. Klebsiella organism in $\mathrm{p} 1$ and $\mathrm{p} 2$ was 0.04 and 0.01 respectively while Streptococci in $\mathrm{p} 2$ was 0.007 .

Conclusion: Gut microbiota have a crucial role in HCV patients especially the non responders compared to the control even the responders need to be followed up to adjust the gut flora of them to the normal because this proved to play an important role in micro environmental changes that lead to hepatocellular carcinoma (HCC).

\section{INTRODUCTION}

Hepatitis C virus (HCV) infection represents an important global cause of chronic hepatitis, cirrhosis and hepatoma [1]. Chronic hepatitis $\mathrm{C}$ is prevalent in many countries as in Egypt (15\%), Pakistan (4.8\%) and China (3.2\%) [2]. The human gastrointestinal tract contains millions of microorganisms with up to 2000 different species of bacteria [3]. The gut flora begin to colonize shortly after birth and plays an important role in keeping the individual healthy by digestion improvement, vitamin production, bile acids generation, and modulation of immune mechanisms of the host [4]. Many factors, including diet, drugs, illness, stress, and lifestyle, affect the structure of community of gut microbiota and microflora, which has a rule in health and [5]. Many studies showed a close relation between the gut microflora and disease development [6]. In recent years, the relationship between the gut 
microbiota and the liver has been studied which is described as 'gut-liver axis' [7]. Many studies documented the involvement of intestinal microflora in alcoholic liver disease (ALD) and non-alcoholic steatohepatitis (NASH), liver cirrhosis and hepatocellular carcinoma (HCC) [8]. However, little is known about the relation between hepatic viruses and, especially hepatitis $\mathrm{C}$ virus infection and intestinal microflora. Here, we give an outline of the current knowledge on the association of the gut microbiota and the course of treatment in chronic hepatitis C patients.

\section{Aim of the Work:}

The aim of the present study is to evaluate the association between gut flora and the response of antiviral therapy for chronic $\mathrm{HCV}$ patients; responders, and non responders.

\section{SUBJECTS AND METHODS}

\section{SUBJECTS:}

This study was performed on 30 patients who were recruited from outpatient clinic of Hepatology, Gastroenterology and Infectious Diseases Department at Benha University Hospital and Benha Fever Hospital in the period from January 2017 to September 2017, in addition to 15 apparently healthy subjects serving as healthy control. Subjects included in this study were classified into the following groups: Group I; included 15 patients with chronic hepatitis C who achieved sustained virological response (SVR), Group II; included 15 patients with chronic hepatitis $\mathrm{C}$ who failed to achieve SVR, and Group III; included 15 apparently healthy subjects served as control group.

\section{Inclusion criteria:}

1) Patients chronically infected with $\mathrm{HCV}$ confirmed with Anti-HCV positive and $\mathrm{HCV}$ RNA by positive PCR.

2) Patients $>18$ years old and $<65$ years old.

3) Patients with platelet count $>50,000 / \mathrm{cmm}$.

4) Patients with hemoglobin level $>10 \mathrm{~g} / \mathrm{dl}$.

5) Patients with INR $<1.7$

6) Patients with total bilirubin $<2 \mathrm{mg} / \mathrm{dl}$.

7) Treatment naïve or treatment experienced.

\section{Exclusion criteria:}

1) Direct serum bilirubin $>2 \mathrm{mg} / \mathrm{dl}$.

2) Serum albumin $<2.8 \mathrm{~g} / \mathrm{dl}$.

3) International Normalization Ratio (INR) $\geq 1.7$

4) Inflammatory bowel syndrome.

5) Extra-hepatic malignancy except after two years of disease-free interval.

6) Pregnancy or inability to use effective contraception.

7) Patients with HBV co-infection.

8) Patients with history of Wilson disease or hemochromatosis.

9) Autoimmune liver disease

All patients were considered eligible to participate in the current study. Patients received 12 weeks regimen of daily sofosbuvir $400 \mathrm{mg}$ with either daclatasvir $60 \mathrm{mg}$ or ledipasvir $90 \mathrm{mg}$. Some of patients received weight-based ribavirin. HCV-RNA PCR was done to assess treatment response at end of 12 weeks after completion of treatment. Treatment outcome was achieving a sustained virological response (SVR), which was defined as "response", and failure to achieve an SVR, which was defined as "non response""

- All laboratory investigations done according to the protocol for $\mathrm{HCV}$ patients as well as US and endoscopy.

\section{Stool culture for Microbita: \\ Specimen collection:}

Stool samples from patients and healthy controls were collected in sterile cups. Stool samples were processed upon delivery in the laboratory on the day of collection.

\section{Organism identification: \\ First day:}

On various selective and differential materials, including MacConkey agar, blood agar and Sabouraud agar, routine bacterial stool cultures are incubated aerobically and anaerobically at $35^{\circ} \mathrm{C}$. Wet and Gram films were done to detect pus cells and bacteria then loopful from the sample was taken to do culture on different media as mentioned.

Second day:

Culture media were examined for bacterial growth. Subcultures were done in cases of mixed growth.

\section{Third day:}

Direct inoculation of bacterial suspension by the VITEK 2 microbial identification system was done to identify species of bacterial flora including Proteus mirabilis, Escherichia coli, 
Bacteroides fragilis, Enterococcus faecalis, and others.

VITEK 2 system can detect more than $90 \%$ of gram-negative and gram positive bacilli within 3 hours [9].

Identification of bacterial microflora was done using the VITEK 2 system (BioMérieux, La Balme les Grottes, France) and by traditional phenotypic testing, involving bacterial morphology and characteristic pigments.

VITEK 2 cards for detection of Gram negative and Gram positive bacilli were used to identify different species of bacterial microflora.

Five steps are included as following:

Step 1: Suspend and wash tubes with $0.45 \%$ saline solution.

Step 2: Put a swab from culture into suspension. Step 3: Adjust the cell density to $0.5 \mathrm{McF}$ arland.

Step 4: Insert the arm of Vitek card into the tube. Step 5: Vitek cards are inoculated with the suspension and loaded in the machine, and the results are obtained after 4 to 8 hours [9].

\section{Statistical Analysis}

\section{Data management}

The clinical data were recorded in a report form. These data were tabulated and analyzed using the computer program SPSS (Statistical Package for Social Science) version 20 to obtain:

\section{Descriptive data}

Descriptive statistics were calculated for the data in the form of:

1) Mean standard deviation $( \pm \mathrm{SD})$ Median and inter-quartile range (IQR) for quantitative data.

2) Frequency and distribution for quantitative data.

\section{Analytical statistics}

In the statistical comparison between the different groups, the significance difference was tested using one of the following tests:
1) Student's $t$-test and Mann-Whitney test: Used to compare mean of two groups of quantitative data of parametric and nonparametric respectively.

2) ANOVA A test (F value) and Kruskal-Wallis test: Used to compare mean of more than two groups of quantitative data of parametric and non-parametric respectively.

3) Inter-group comparison of categorical data was performed by using Chi square $\left(X^{2}\right.$-value) and Fisher's exact test (FET).

$$
\begin{aligned}
& x^{2}=\frac{\sum(\text { observed }-\exp e c t e d)^{2}}{\text { Expected }} \\
& \text { Expected }=\frac{\text { col.total } x \text { row total }}{\text { Grand total }}
\end{aligned}
$$

A $\mathrm{P}$ value $<0.05$ was considered statistically significant $\quad\left(^{*}\right)$ while $>0.05$ statistically insignificant. $\mathrm{P}$ value $<0.01$ was considered highly significant $(* *)$ in all analyses.

\section{RESULTS}

No significant difference between the groups in laboratory investigations and US finding tables $(1,2)$. Also there is no statistical significant difference as regards stool culture for microbiota (E coli, Enterococcus faecalis and Bacteroides) Table (3), Figure (1). But there was statistically significant difference between (responders and non responders) and control, where p1 comparison between control and responders, $\mathrm{p} 2$ between control and non responders, p3 between responders and non responders. Enterobacter organism in p2, p3 was $<0.001$ and $<0.005$ respectively. Proteus and Clostridium perfringens in p2 was 0.009 and 0.04 respectively. Klebsiella organism in $\mathrm{p} 1$ and $\mathrm{p} 2$ was 0.04 and 0.01 respectively while Streptococci in p2 was 0.007 . Table (3), figure (1). 
Table 1: General conditions of patients in the three groups.

\begin{tabular}{|l|c|c|c|}
\hline \multirow{2}{*}{} & \multicolumn{3}{|c|}{ Groups } \\
\cline { 2 - 4 } & $\begin{array}{c}\text { Responders } \\
(\mathrm{n}=15)\end{array}$ & $\begin{array}{c}\text { Non responders } \\
(\mathrm{n}=15)\end{array}$ & $\begin{array}{c}\text { Control } \\
(\mathrm{n}=15)\end{array}$ \\
\hline Sex (male/female) & $11 / 4$ & $8 / 7$ & $10 / 5$ \\
\hline Age (years) & $56.67 \pm 5.82$ & $52.0 \pm 7.55$ & $36.27 \pm 14.01$ \\
\hline Special habits & $3(20.0)$ & $4(26.7)$ & $1(6.7)$ \\
$\quad$ Smoker & $12(80.0)$ & $11(73.3)$ & $14(93.3)$ \\
\hline Non smoker & $12.64 \pm 1.83$ & $13.33 \pm 1.54$ & $12.67 \pm 1.12$ \\
\hline Hemoglobin $(\mathrm{gm} / \mathrm{dl})$ & $6.37 \pm 3.69$ & $6.34 \pm 1.74$ & $6.88 \pm 1.42$ \\
\hline WBCs x 1000/cmm & $210.6 \pm 83.02$ & $201.33 \pm 78.75$ & $317.67 \pm 60.5$ \\
\hline Platelets x100/cmm & $38.53 \pm 8.42$ & $36.67 \pm 11.35$ & $31.27 \pm 5.81$ \\
\hline Urea (mg/dl) & $1.08 \pm 0.34$ & $0.97 \pm 0.33$ & $0.96 \pm 0.19$ \\
\hline Creatinine $(\mathrm{mg} / \mathrm{dl})$ & $56.73 \pm 43.35$ & $58.27 \pm 30.61$ & $23.4 \pm 7.93 \mathrm{ab}$ \\
\hline AST (IU/L) & $49.27 \pm 21.25$ & $58.67 \pm 32.2$ & $24.67 \pm 6.15 \mathrm{ab}$ \\
\hline ALT (IU/L) & $1.09 \pm 0.58$ & $0.85 \pm 0.31$ & $0.95 \pm 0.22$ \\
\hline Total bilirubin $(\mathrm{mg} / \mathrm{dl})$ & $0.35 \pm 0.45$ & $0.19 \pm 0.09$ & $0.23 \pm 0.09$ \\
\hline Direct bilirubin $(\mathrm{mg} / \mathrm{dl})$ & $3.92 \pm 0.36$ & $3.98 \pm 0.41$ & $3.95 \pm 0.30$ \\
\hline Serum albumin $(\mathrm{g} / \mathrm{dl})$ & $12.59 \pm 0.88$ & $13.53 \pm 1.92$ & $12.82 \pm 0.84$ \\
\hline PT (sec) & & & \\
\hline
\end{tabular}

Table 2: Abdominal ultrasonographic findings in responders and non responders groups.

\begin{tabular}{|l|c|c|}
\hline \multirow{2}{*}{} & \multicolumn{2}{|c|}{ Groups } \\
\cline { 2 - 3 } & $\begin{array}{c}\text { Responders } \\
(\mathrm{n}=15)\end{array}$ & $\begin{array}{c}\text { Non responders } \\
(\mathrm{n}=15)\end{array}$ \\
\hline Liver size & $6(40.0)$ & $6(40.0)$ \\
Enlarged & $9(60.0)$ & $6(60.0)$ \\
Average & $0(0.0)$ & $0(0.0)$ \\
Shrunken & $15(100)$ & $15(100)$ \\
\hline Liver texture & $0(0.0)$ & $0(0.0)$ \\
Normal & $0(0.0)$ & $0(0.0)$ \\
Coarse & & \\
Cirrhotic & $15(100)$ & $15(100)$ \\
\hline Homomgenity & $0.89 \pm 0.19$ & $0.98 \pm 0.23$ \\
Homogenous & $0.9(0.7-1.1)$ & $0.9(0.8-1.2)$ \\
\hline PV diameter (cm) & $15(100)$ & $15(100)$ \\
\hline PV patency & $10(66.7)$ & $8(53.3)$ \\
Patent & $5(33.3)$ & $6(40.0)$ \\
\hline Spleen size & $0(0.0)$ & $1(6.7)$ \\
Normal & $0(0.0)$ & $2(13.3)$ \\
Enlarged & & \\
Surgically removed & & \\
\hline Spleen collaterals & & \\
\hline
\end{tabular}


Table 3: Results of VITEK 2 in all studied groups.

\begin{tabular}{|l|c|c|c|c|c|c|}
\hline Organism & Control $\mathbf{( N = 1 5 )}$ & $\begin{array}{c}\text { Responders } \\
(\mathbf{N = 1 5})\end{array}$ & $\begin{array}{c}\text { Non responders } \\
(\mathbf{N = 1 5})\end{array}$ & $\mathbf{P 1}$ & $\mathbf{P 2}$ & $\mathbf{P 3}$ \\
\hline $\begin{array}{l}\text { Escherichia coli } \\
\text { Enterococcus } \\
\text { faecalis }\end{array}$ & $15 / 15(100 \%)$ & $15 / 15(100 \%)$ & $15 / 15(100 \%)$ & - & - & - \\
\hline Bacteroides fragilis & $15 / 15(100 \%)$ & $15 / 15(100 \%)$ & $15 / 15(100 \%)$ & - & - & - \\
\hline Enterobacter & $6 / 15(100 \%)$ & $15 / 15(100 \%)$ & $15 / 15(100 \%)$ & - & - & - \\
\hline Proteus mirablis & $6 / 15(40.0 \%)$ & $8 / 15(53.3 \%)$ & $13 / 15(86.7 \%)$ & 0.30 & $<0.001^{* *}$ & $0.005^{* *}$ \\
\hline Klebsiella & $5 / 15(33.3 \%)$ & $9 / 15(60.0 \%)$ & $11 / 15(73.3 \%)$ & 0.12 & $0.009^{* *}$ & 0.27 \\
\hline $\begin{array}{l}\text { Clostridium } \\
\text { perfringens }\end{array}$ & $10 / 15(66.7 \%)$ & $7 / 15(46.7 \%)$ & $6 / 15(40.0 \%)$ & 0.12 & $0.04^{*}$ & 0.59 \\
\hline Staph aureus & $5 / 15(33.3 \%)$ & $6 / 15(40.0 \%)$ & $6 / 15(40.0)$ & 0.59 & 0.59 & 1.0 \\
\hline Streptococci & $3 / 15(20.0 \%)$ & $5 / 15(33.3 \%)$ & $8 / 15(53.3 \%)$ & 0.24 & $0.007 * *$ & 0.12 \\
\hline Clostridium tetani & $3 / 15(20.0 \%)$ & $6 / 15(40.0 \%)$ & $5 / 15(33.3 \%)$ & 0.09 & 0.24 & 0.59 \\
\hline Pseudomonas & $1 / 15(6.7 \%)$ & $2 / 15(13.3 \%)$ & $1 / 15(6.7 \%)$ & 0.67 & 1.0 & 0.67 \\
\hline
\end{tabular}

P1: control \& responders

p2:control \& non responders

p3: responders \& non responders

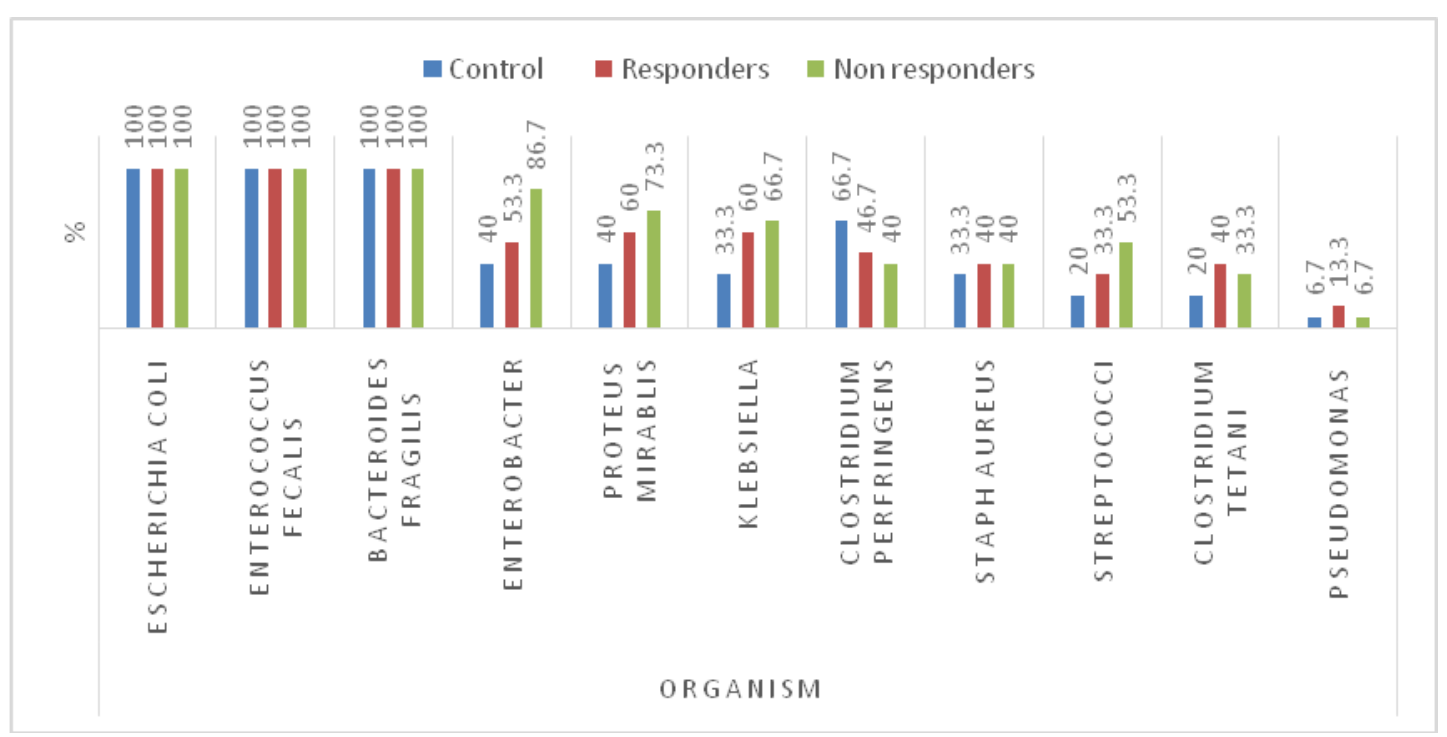

Figure 4: Results of VITEK 2 in all studied groups.

\section{DISCUSSION}

Still there is percentage of $\mathrm{HCV}$ patients not responding to Direct Acting Antiviral Agents (DAAS), even the responder HCV patients need to follow up.

Many studies showed a close relation between the gut microflora and disease development [6]. In recent years, the relationship between the gut microbiota and the liver has been studied which is described as 'gut-liver axis' [7].

However, little is known about the relation between hepatic viruses especially the hepatitis $\mathrm{C}$ virus infection and intestinal microflora. In this study, we provide an overview of the current knowledge on the relationship between the intestinal microflora and the course of treatment of chronic hepatitis $\mathrm{C}$ and describe the diversity of gut microbiota in responders and non responders and comparing them also with healthy people.

In this study, there was no statistically significant difference between the responders and non responders groups as regarding age with a mean age 52 years. Table (1)

Similar results was detected by Paul and his colleagues (2016) who reported the same results and concluded that SVR not affected by age of patients but it gives more success rate when age of patients less than 50 years[10], in addition to Asselah and colleagues (2017) who documented that no statistically significant difference between the responders and non responders as regards age with a mean age 56 years[11], on the other hand, Hezode and his partners (2017) found that age

El-Badawy et al., Afro-Egypt J Infect Endem Dis 2019; 9(4):280-286

https://aeji.journals.ekb.eg/

http://mis.zu.edu.eg/ajied/home.aspx 
older than 40 years is an independent predictor of a reduced SVR [12].

In this study, there was no significant difference as regards ALT, AST, serum albumin and INR level between responders and non responders. Table (2).

This finding is in agreement with the finding of Sato and colleagues (2017) who stated that no significant difference in ALT, AST and INR level between responders and non responders [13]. Similar results were detected by Asselah and colleagues (2017) who said that baseline alanine aminotransferase (ALT) levels were not associated with treatment response [11].Table (2).

The current study shows an increase in Clostridium tetani in HCV-infected patients especially responders. This is in agreement with Pérez and colleagues (2019)[14].

The study revealed that there is no difference between all studied groups as regards Bacteroides fragilis being present in the stool samples of $100 \%$ of all subjects. This finding was in agreement with Pérez and colleagues (2019) who reported 100\% incidence in both responders and non responders [14].table (3)

We observed a higher abundance of Enterobacter in HCV-infected patients. This result was in accordance with that of Bajaj (2016) who showed a distinctive pattern of gut microbiota in the chronic hepatitis C patients when compared with the healthy individuals including Enterobacter and Clostridium species [15].

Concerning Clostridia, our study showed that Clostridium perfringens were more in healthy subjects while Clostridium tetani were more in $\mathrm{HCV}$-infected patients .

Statistically significant difference between the patients (responders and non responders) and control, where p1 comparison between control and responders, p2 between control and non responders, p3 between responders and non responders. Enterobacter organism in p2, p3 was $<0.001$ and $<0.005$ respectively. Proteus and Clostridium perfringens in $\mathrm{p} 2$ was 0.009 and 0.04 respectively. Klebsiella organism in p1 and p2 was 0.04 and 0.01 respectively while Streptococci in $\mathrm{p} 2$ was 0.007 . Up till now there are no similar studies in Egypt to compare with. Conclusion: Gut microbiota have a crucial role in HCV patients especially the non responders compared to the control even the responders need to be followed up to adjust the gut flora of them to the normal because this proved to play an important role in micro environmental changes that lead to hepatocellular carcinoma (HCC).

\section{Acknowledgment:}

We would like to thank all participants of this study. We would also like to thank Prof. Reda Mohammed Salem El-Badawy, Dr. Mohammed El-Sayed El-Shewi, Prof. Naglaa Fathy Ebrahim Al-Husseini, and Dr. Rasha Abdel-Hameed ElSayed Ali, and all the Physicians from the Hepatology, Gastroenterology and Infectious Diseases Department at Benha University Hospital for their help in patient's recruitment, collection of demographic data from the patients included in the study and bioinformatics analyses.

Ethical approval: Approved.

Funding:None.

Conflict of interest: The authors declare that they have no conflict of interest.

\section{REFERENCES}

1. Neal KR, Ramsay S, Thomson BJ, Irving WL. Excess mortality rates in a cohort of patients infected with the hepatitis $\mathrm{C}$ virus: a prospective study. Gut 2007; 56:1098-104.

2. World health organization http://www.who.int/mediacentre/factsheets/fs164/ en/index.html Hepatitis C, Fact sheet $N^{\circ} 164$, July 2013.

3. Minemura M, Shimizu Y.: Gut microbiota and liver diseases. World J Gastroenterol 2015; 21: 1691e1702.

4. Wan M, El-Nezami H. Targeting gut microbiota in hepatocellular carcinoma: probiotics as a novel therapy. Hepatobiliary Surg Nutr 2018; 7: 11e20.

5. Henao-Mejia J, Elinav E, Jin C, Hao L, Mehal WZ, Strowig T, et al. Inflammasome-mediated dysbiosis regulates progression of NAFLD and obesity. Nature 2012; 482:179e185.

6. Biedermann L, Rogler G. The intestinal microbiota: its role in healthand disease. Eur $\mathbf{J}$ Pediatr 2015; 174(2):151-167.

7. Fukui $\mathrm{H}$. Gut microbiota and host reaction in liver diseases. Microorganisms 2015; 3(4):759791.

8. Abenavoli L, Scarpellini E, Rouabhia S, Balsano C, Luzza F. Probiotics in non alcoholic fatty liver disease: which and when. Ann Hepatol 2013; 12(3):357-363.

9. Ligozzi M, Bernini C, Bonora M, De Fatima M, Zuliani J, Fontana R, et al. Evaluation of the VITEK 2 System for Identification and Antimicrobial Susceptibility Testing of Medically Relevant Gram-Positive Cocci. J ClinMicrobiol. 2002; 40(5): 1681-1686. 
10. Paul C, Asselah T, Reddy K, Mobashery N, Redman R, Vilchez RA, et al. Ombitasvir plus paritaprevir plus ritonavir with or without ribavirin in treatment-naïve and treatmentexperienced patients with genotype 4 chronic hepatitis virus infection. Lancet 2016; 385: 2502 09.

11. Asselah T, Reddy KR, Hassanein T, Berenguer M, Fleischer-Stepniewska K, Marcellin P, et al. Ombitasvir plus paritaprevir plus ritonavir with or without ribavirin in treatment-naive and treatment-experienced patients with genotype 4 chronic hepatitis C virus infection. Lancet 2017; (15) 605-608.
12. Hézode C, Qaqish RB, ElKhashab M, Hassanein T, Papatheodoridis G, Feld J, et al. Ombitasvir, paritaprevir, and ritonavir plus ribavirin in adults with hepatitis $\mathrm{C}$ virus genotype 4 infection and cirrhosis. Lancet 2017; (16)30001-2.

13. Sato K, Yamazaki Y, Ohyama T, Kobayashi T, Horiguchi N, Kakizaki S, et al. Combination therapy with daclatasvir and asunaprevir for dialysis patients infected with hepatitis $\mathrm{C}$ virus. World J Clin Cases 2017; 16: 88-93.

14. Pérez-Matute $P$, Íñiguez M, Villanueva-Millán MJ, Recio-Fernández E, Vázquez AM, Sánchez $\mathrm{SC}$, et al. Short-term effects of direct-acting antiviral agents on inflammation and gutmicrobiota in hepatitis C-infected patients. Eur J Intern Med 2019; 67:47-58.

15. Bajaj JS. Potential mechanisms of action of rifaximin in the management of hepatic encephalopathy and other complications of cirrhosis. Aliment Pharmacol Ther 2016; 43(Suppl 1): 11-26. 